\title{
Acta
Biochimica
Polonica
}

75th Anniversary of the M. Nencki

Institute of Experimental Biology

Vol. 40 No. $3 / 1993$

QUARTERLY

Minireview

\section{Gangliosides in the repair of brain cholinergic neurons*}

\author{
Barbara Oderfeld-Nowak ${ }^{a, c}$, Fiorella Casamenti ${ }^{b}$ and Giancarlo Pepeu ${ }^{b}$ \\ ${ }^{a}$ Department of Neurophysiology, M. Nencki Institute of Experimental Biology, \\ L. Pasteura 3, 02-093 Warsaw, Poland \\ ${ }^{b}$ Department of Preclinical and Clinical Pharmacology, University of Florence, \\ Viale Morgagni 65, 50134 Florence, Italy
}

Received 9 June, 1993

In 1976 it was reported that the brains of patients dying of Alzheimer's disease are characterized by a marked loss of cholinergic markers in the cortex and hippocampus (cf. [1]). Subsequently, proponents of the cholinergic hypothesis of dementia suggested that the changes which reflect damage to afferent pathways projecting from the basal forebrain make an important contribution to the intelectual decline that is typical of Alzheimer's disease (cf. [1 -3]). Moreover, changes in cholinergic neurons of the forebrain nuclei have been described in aging (cf. [4]), more subtle in comparison to those in senile dementia of Alzheimer's type, but nevertheless relevant.

Although it is now well known that several neurotransmitter systems are impaired in Alzheimer's disease as well as in aging, the cholinergic deficits are the most clearly defined neurochemical abnormalities. Consequently, great attention has been drawn to the search for effective "cholinergic therapies". Drawing upon the analogy with Parkinson's disease, in which replacement therapy was strikingly suc- cessful, the cholinomimetic therapies were first proposed. Basically, four strategies were used to correct the cholinergic deficits in patients. These strategies are: precursor loading, the use of cholinesterase inhibitors, the combination of precursor loading and cholinesterase inhibition, and the administration of cholinergic muscarinic agonists [5]. However, none of these strategies seems to produce appreciable clinical change in the cognitive function or correct the functional and behavioral deficits in demented patients. In addition, the use of cholinergic drugs has been limited because of their short duration of action and the occurrence of disabling side effects. Thus, there is an urgent need for an effective treatment which would not only ameliorate the symptoms of dementia, but prevent or at least slow down the progression of the disease.

There is increasing evidence that survival and maintenance of function of cholinergic neurons in the central nervous system (CNS) ${ }^{1}$ depends on the presence of nerve growth factor (NGF) (cf. $[6,7])$. Thus, pharmacological intervention

*B. Oderfeld-Nowak acknowledges support by a Statutable grant from the State Committee for Scientific Research to the Nencki Institute. During the preparation of some parts of this article B. Oderfeld-Nowak was supported by a CNR fellowship

'Correspondence should be addressed to: Prof. Barbara Oderfeld-Nowak, Department of Neurophysiology, M. Nencki Institute of Experimental Biology, L. Pasteura 3, 02-093 Warsaw, Poland

${ }^{1}$ Abbreviations used: ACh, acetylcholine; ChAT, choline acetyltransferase; CNS, central nervous system; GM1, monosialoganglioside; i.c.v.,intracerebroventricular(ly);i.p., intraperitoneally;NBM, nucleus basalis magnocellularis; NGF, nerve growth factor 
aimed at enhancing or mimicking the action of neuronotrophic factors, including NGF, could prevent the progression of degeneration.

The interest in studying potential reparative effects of gangliosides on brain cholinergic neurons was prompted by the observations made in early 1980 'ies that ganglioside mixture (GM1, GD1a, GD1b, GT1b ) facilitated the recovery of cholinergic parameters in the hippocampus of rats with septal nucleus lesions [8, 9]. This interest has been further highlighted by the findings indicating the responsiveness of cholinergic neurons to exogenous NGF, and also by evidence from in vitro studies, pointing to the cooperation between these two groups of substances (cf. $[6,7,10]$ ). These findings suggested that administration of neurotrophic agents like gangliosides, may be an alternative to other, so far unsuccessful strategies to correct the cholinergic deficiencies of the brain.

This short review deals with the action of gangliosides on impaired magnocellular cholinergic neurons in some experimental lesion model systems. Special emphasis is placed on the evidence for synergistic effects of gangliosides and NGF. Some of the proposed mechanisms by which gangliosides are effective in protecting cholinergic neurons against damage are also explored.
Gangliosides: biology and general CNS pharmacology

Gangliosides are normal components of cellular membranes and are particularly abundant in the CNS. Their hydrophobic tails (composed of an amino-alcohol, sphingosine, and a fatty acid) are incorporated into the neuronal membrane while its glucidic parts, including one or more sialic acids, protrude on the outside of the cell (see Fig. 1, showing the structure of ganglioside GM1, with one sialic acid group).

Due to their location and orientation on the cellular membranes gangliosides play an important part in modulation of receptor-mediated signal transduction including the second messenger systems, membrane enzyme activity and membrane permeability to ions, and adhesion processes, e.g. cell-cell and cell-substrate $[10,11]$.

For the first time, the neurotrophic activity of gangliosides in vivo has been described in the second half of the seventies, and concerned their beneficial effects upon the injured peripheral nervous system (cf. [10]). These initial findings were subsequently confirmed and extended by many neurobiologists, most of whom used in their studies the mixture of four main brain gangliosides (GM1, GD1a, GD1b, GT1b).

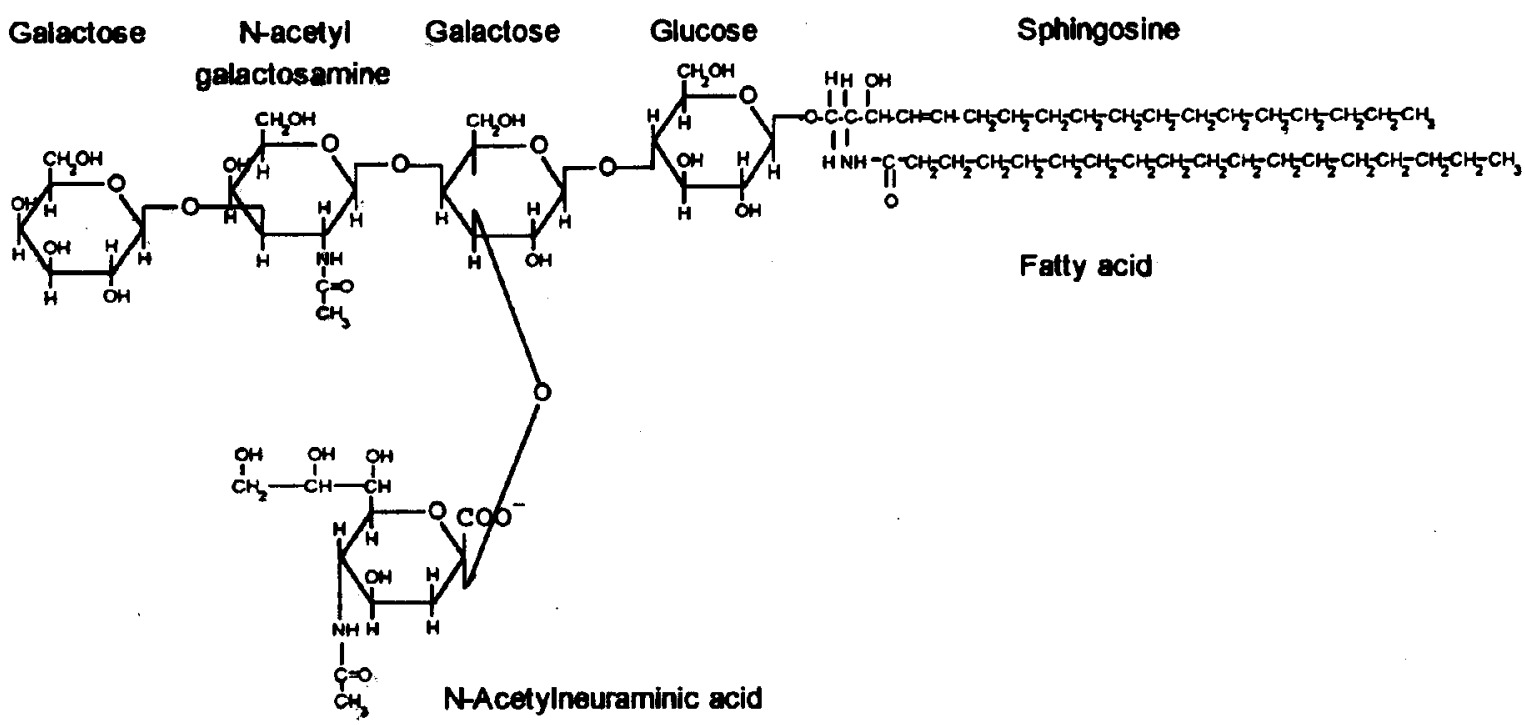

Fig. 1. The GM1 ganglioside with the hydrophobic ceramide moiety and the hydrophilic oligosaccharide moiety containing neuraminic acid attached to the internal galactose residue. 
In the early 1980's was began a detailed study on the effects of systemically applied gangliosides in the CNS following damage $[8,9]$. Subsequently, the single ganglioside, GM1 (Fig. 1), was chosen for detailed study after the demonstration of: a) specific role played by endogenous GM1 in various neuroplastic phenomena during growth and in adult animals, b) the ability of exogenous GM1 to facilitate the action of neuronotrophic factors while antagonizing neurotoxic effects in vitro (cf. [10, 12]), and c) ability of GM1 when given systemically, to penetrate the CNS and reach there concentration comparable with those effective in vitro $[13,14,15]$. In addition, an important role has been attributed to GM1 in the regulation of the neuritogenic processes of CNS neuronal development and regeneration in the mature animal. In adult animals, neuritic elongation has been postulated to correlate with GM1 concentration on the cell membrane, suggesting that such a compound may regulate reparative phenomena.

From all these observations it has been concluded that GM1 in the CNS is fundamental in modulating neuronal responses to the extracellular signals involved in the regulation of the expression of neuronal plasticity phenomena, of which neuritic growth is an example.

A large number of publications have appeared over the last decade describing the effects of GM1 in different brain lesion models, including traumatic, toxic or ischemic damage, involving different neuronal types [10, 12, 16, 17]. The beneficial effects of GM1 treatment were reflected in the recovery of a variety of morphological, biochemical, functional and behavioral parameters.

Both from the historical and practical point of view the effects of gangliosides upon the damaged cholinergic brain neurons attract major attention.

\section{Ganglioside GM1 in rescuing damaged choliner-} gic basal forebrain neurons

Because of the evidence implicating the basal forebrain cholinergic system in the pathology of Alzheimer's disease (cf. [1 - 3]) and other dementias, as well as in normal aging (cf. $[2,4]$ ), this system, in laboratory animals, may serve as a model for the diseased state in humans. Figure 2 shows a schematic representation of the cholinergic basal forebrain (magnocellular) system in rat.

The damage and destruction of cholinergic neurons or the pathways in basal-cortical system projecting from nucleus basalis magnocellularis (NBM) to the cortex, or in septo-hippocampal system projecting from the septum to the hippocampus, brought about by electrolytic, mechanical or neurotoxic lesions, give rise to the conditions which mimick the cholinergic deficits in dementia and some of its cognitive alterations. Although the neurodegenerative processes occurring in cholinergic neurons in dementia and aging seem to be pro-

Fig. 2. Schematic representation of the sagittal section of the rat brain, showing the pathways of

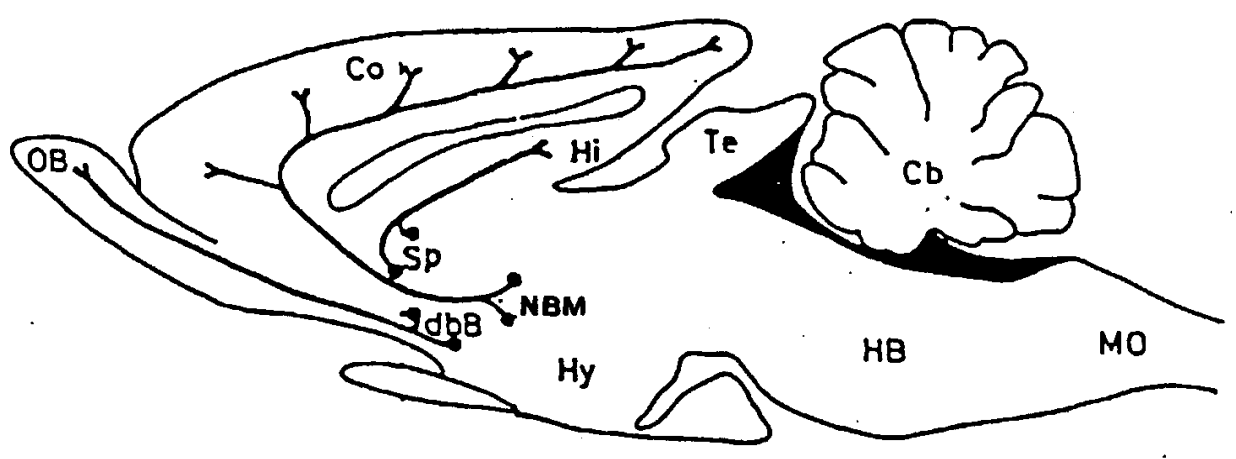
the magnocellular cholinergic system originating from the basal forebrain nuclei.

Ventricular space is shown in black. Abbreviations: $\mathrm{Cb}$, cerebellum; Co, neocortex; $\mathrm{DB}$, diagonal band of Broca; $\mathrm{HB}$, hindbrain; $\mathrm{Hi}$, hippocampus; $\mathrm{Hy}$, hypothalamus; MO, medulla oblongata; NBM, nucleus basalis magnocellularis (of Meynert); $\mathrm{OB}$, olfactory bulb; Sp, septum; St, corpus striatum; Te, optic tectum. 
gressing slowly, the end results are comparable to those occurring in the more rapidly progressing neurodegenerative events in lesioned experimental animals.

It was demonstrated for the first time in early 1980 's that ganglioside mixture prompted the recovery of cholinergic fiber parameters, impaired due to anterograde degeneration of these fibers in consequence of septal nucleus lesions [8, 9]. A similar effect was observed further in the same experimental paradigm, when using a pure GM1 preparation [18]. Subsequently, a similar effect was observed in a septohippocampal pathway lesion model [19, $20,21]$. In these studies the effective dose of GM1 has been established for intraperitoneal or intramuscular injection, which, similarly as it was found for other experimental paradigms, was found to be between 20 and $30 \mathrm{mg} / \mathrm{kg}$ per day.

Several other conditions for effective treatment with gangliosides were established too, for example the structural requirements concerning the ganglioside molecule. On checking the effect of various GM1 derivatives (e.g. methyl ester or methyl-alcohol of GM1) it was found that, in contrast to the situation in vitro, the presence of a negative charge in the molecule of ganglioside (cf. Fig. 1) is a prerequisite of the in vivo effects $[22,23]$. This fact may have something to do with as yet unidentified requirement for the penetration of the agent through the blood-brain barrier.

It has also been found that the effect of GM1 at the target level is related to the magnitude of the target's denervation, although this was observed only when the lesion spared a part of connections [18].

In a model, in which various degrees of fiber degeneration along the septotemporal axis of hippocampus were produced by different lesions, the maximal effect of GM1 counteracting impairment of cholinergic nerve fiber markers was seen in the parts maximally denervated $[19,21]$ and Fig. 3. As it is discussed further, this result suggests the dependence of GM1 action upon the level of injury-evoked endogenous neurotrophic factors.

Other models in which anterograde degeneration of cortically projecting fibers with a con-

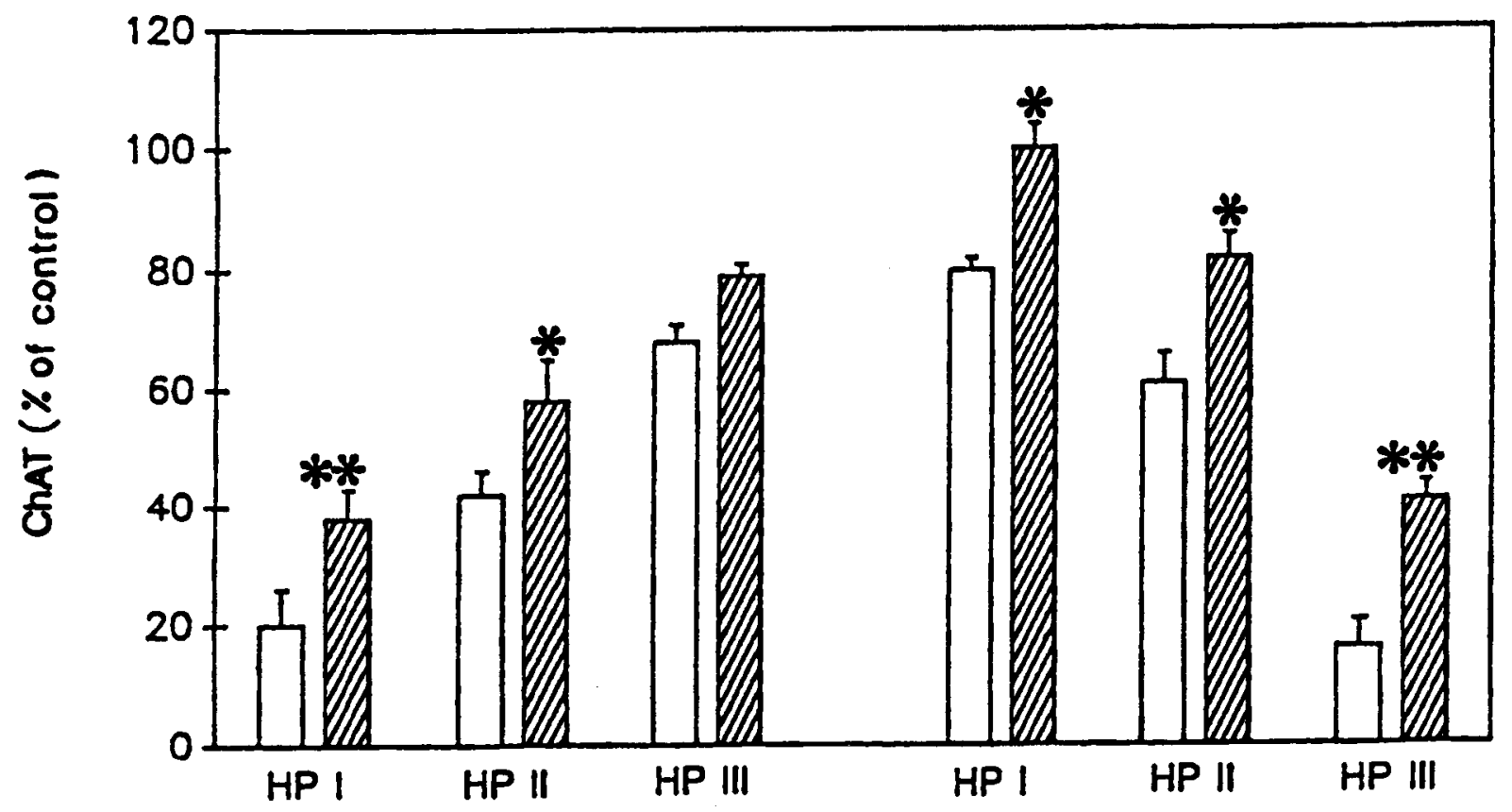

Fig. 3. Effect of GM1 (30 mg/kg per day, i.p.) treatment upon choline acetyltransferase activity (ChAT) in three consecutive hippocampal parts (HP I, II, III) along their septotemporal axis, 6 days after partial lesions of the dorsal hippocampal afferents: left - after electrolytic lesion in supracallosal area, right-after knife lesion of lateral fimbria.

As shown, the two lesions evoke a differential, mirror like, degree of degeneration of cholinergic fibers in particular parts of the hippocampus, expressed in changes of ChAT activity. The effect of GM1 is seen in all hippocampal parts, but is most pronounced in the most degenerated parts. Open bars, untreated; hatched, GM1 treated; $P<0.05$ and ${ }^{* *} P<0.01$ versus untreated (calculated from [22] and [20]). 
comitant loss of cholinergic markers and behavioral deficits takes place, consisted in cytotoxic or electrolytic stereotaxic lesions of NBM. In such models, similarly as in the described above septo-hippocampal one, GM1 effects at the target level (cortex) were demonstrated [24 -29] including prevention of the decline in the number of cholinergic parameters: ChAT activity (cf. Fig. 6), high affinity choline uptake and $\mathrm{ACh}$ release. In addition, this treatment also restored impaired behavioral performance [29].

The lesions of the pathways and/or target structures bring about profound retrograde degenerative changes in the respective source of innervation. It is to be kept in mind that the involvement of cholinergic neurons in the nucleus of Meynert in Alzheimer's disease, could be either a primary factor in the pathology, or alternatively, a factor secondary to a primary cortical lesion (cf. [1 - 3]). Thus, it is interesting to observe retrograde changes in cholinergic neurons occurring in such circumstances in model conditions, and see whether GM1 could prevent them. The lesions of septo-hippocampal projections and, even more, a drastic intervention such as the ablation of the whole target (hippocampus) lead to retrograde changes in the septum expressed by several manifesta- tions, as evidenced by morphometric and immunocytochemical studies, including the apparent loss of the immunostaining for ChAT in medial septal nuclei (Fig. 4) [30, 31]. These changes are perhaps partly due to the actual cell death and partly are a reflection of the drastic cell shrinkage with diminished expression of ChAT antigenic sites. GM1 administered in such a model [30] (Fig. 4) attenuates the changes and results in a considerable protection of cholinergic neurons.

An interesting model has been elaborated to study the retrograde degenerative involvement of cholinergic neurons in nucleus basalis magnocellularis and their modulations by pharmacological manipulation (cf. [10]). It has been, namely, demonstrated that extensive devascularizing (thus ischemic) neocortical lesions lead to retrograde damage of this nucleus. Like in the septum, the retrograde changes are expressed by several manifestations, including shrinkage in the cholinergic neurons, loss of the neurites. In the NBM these changes become apparent later than those observed in the septum $[32,33]$. Also functionally the animals display behavioral abnormalities [34]. These biochemical and anatomical degenerative changes and their behavioral consequences can be completely prevented in corti-

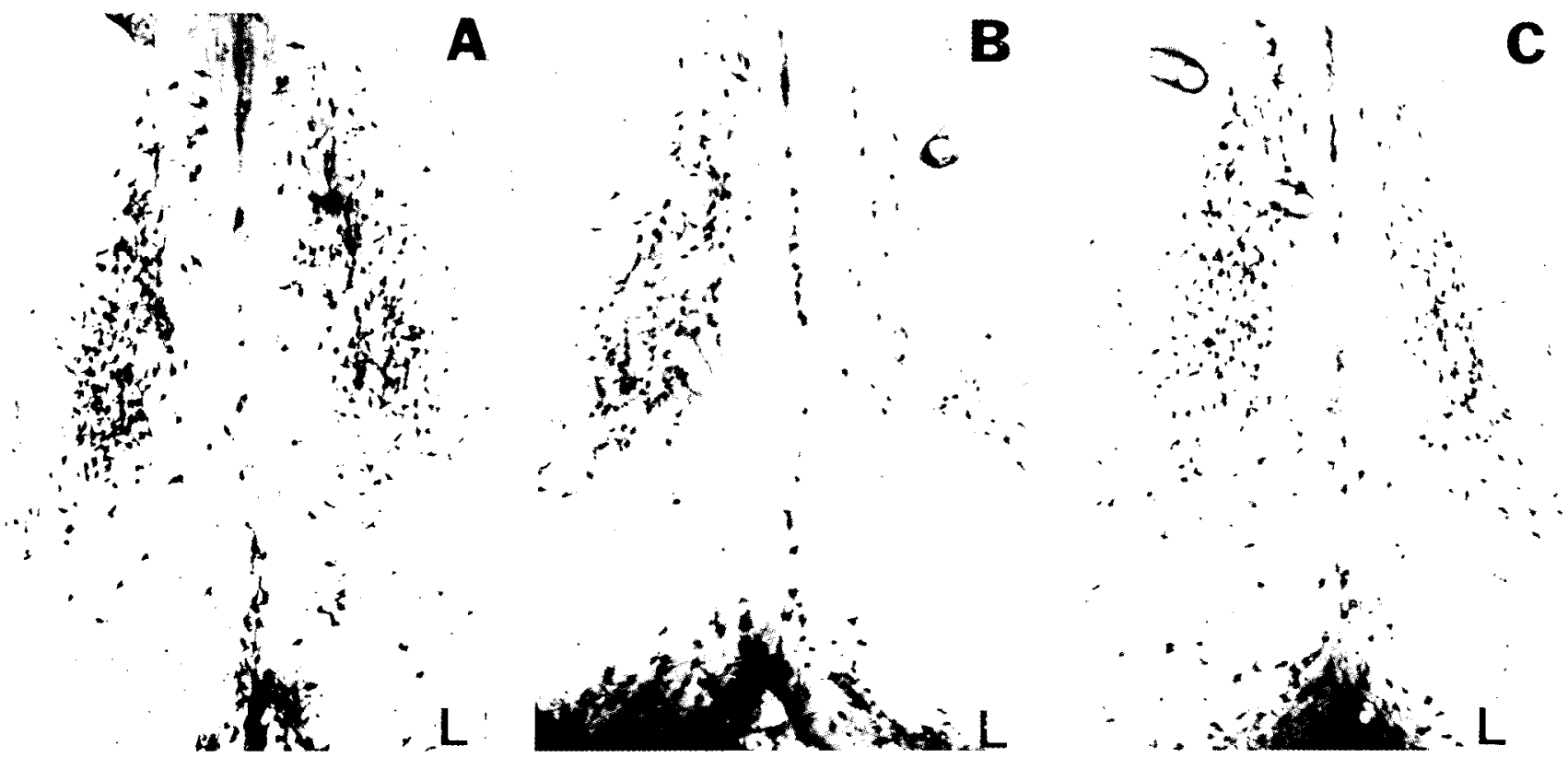

Fig. 4. Photomicrograph of the rat medial septal nucleus stained for the immunohistochemical detection of ChAT.

A, normal animal; B, following removal of the left hippocampus; note the marked loss of cholinergic cells from the left medial septum; $C$, following removal of the left hippocampus in an animal receiving GM1; the majority of the cholinergic cells in the left medial septum are preserved; $\times 35$; L, left; (írom [30], with permission). 
cally lesioned rats by administration intraperitoneally of $30 \mathrm{mg} / \mathrm{kg}$ per day of GM1 for 30 days beginning immediately postlesion [32 35], (cf. also [10]). Using this model, other ways of GM1 administration were also applied. GM1 given i.c.v. in a dose of $5 \mathrm{mg} / \mathrm{kg}$ per day for 7 days resulted in significant improvement of impaired cholinergic parameters [33]. Even more spectacular improvement was obtained with the use of microencapsulated GM1 [36], (cf. Fig. 5). The decrease in ChAT activity, ChAT immunoreactivity and cell shrinkage was prevented. A vast amount of data was obtained on rats, which by obvious reasons remain the most common model for different manipulations involving drug effects. It has to be stressed, however, that very recently [37] it was demonstrated that as in rodent NBM, magnocellular ChAT and the p75 NGF receptor-immunoreactive neurons of nonhuman primate NBM, undergo degeneration after neocortical ischemic injury, and that complete protection against these changes has been achieved by GM1 treatment. Moreover, it has been found that GM1 treatment is able to avert degenerative changes in these NBM neurons for an extended time, at least six months after neocortical lesioning.

It has to be mentioned that GM1 is not always protective against the lesion-induced impairments. This holds for some kinds of neurotoxic damage, although GM1 exerted positive effects in cases of ibotenic acid [29], colchicine [38] or vincristine [27] neurotoxicity. For example, it has been demonstrated that GM1, at the same doses which protected against the effect of devascularization was inactive against the retrograde degeneration of the basal forebrain cholinergic neurons induced by cortical application of kainic acid [39]. This lack of effeci indicated that GM1 requires "permissive conditions" in order to exert its reparative function (see discussion in the next section). GM1 also failed to prevent NBM degeneration in cortically [40] and NBM [29] lesioned aged rats; this could result from the diminished production of endogenous neurotrophic factors in these conditions, thus on the lack of sufficient "permissive conditions". On the other hand, it has been recently described [41] that GM1 treatment significantly enhanced the declined high affinity choline uptake in the hippocampus and striatum, but not in the cortex in senescent rats.

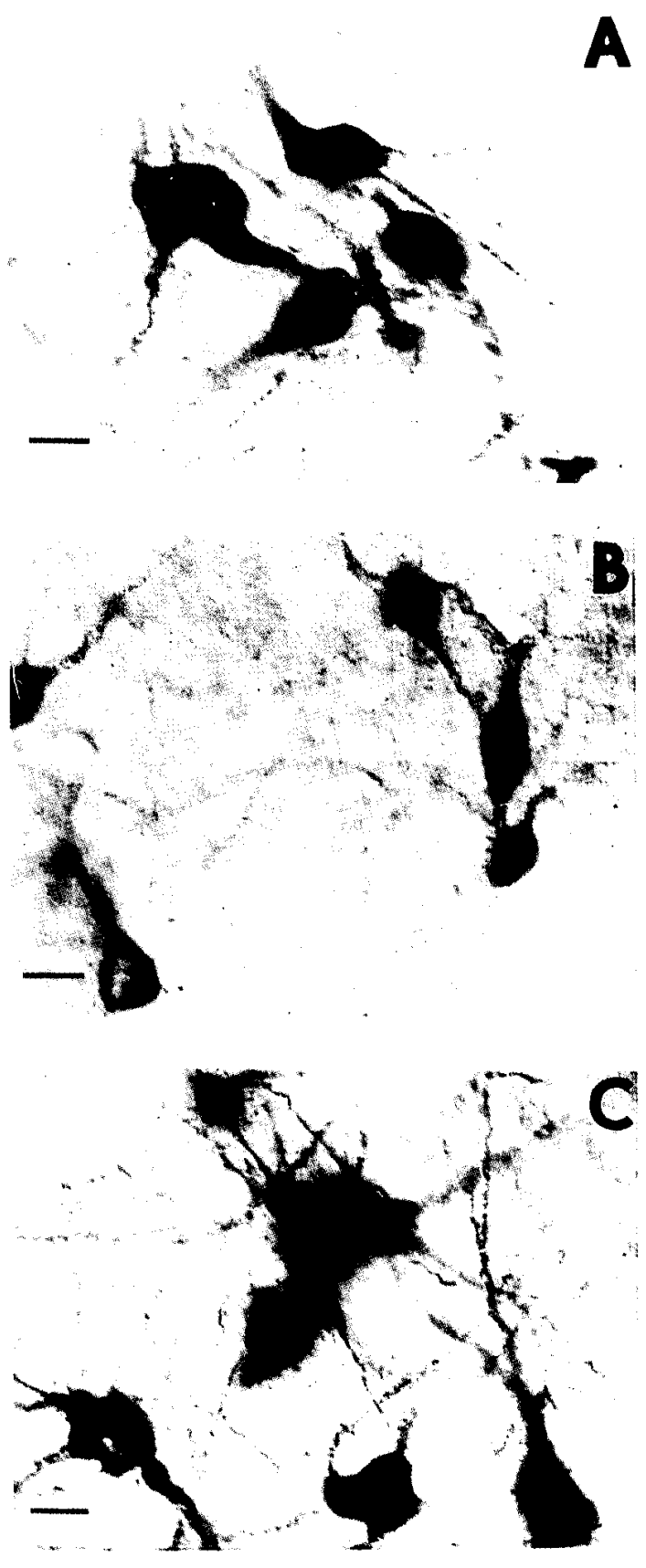

Fig. 5. The effect of microencapsulated GM1 treatment on the morphology of cholinergic neurons in the NBM.

Photomicrographs of representative fields of the NBM ChAT immunoreactive neurons from the control (A), lesioned (B), and lesioned, GM1 treated (C). Bars $=20 \mu \mathrm{m}$. Animals were perfused with $4 \%$ paraformaldehyde 30 days postoperatively (from [36], with permission).

In general, it seems that GM1 is usually effective only when there is an injury or an ongoing degenerative, or progressing (as in development) process, provided that the "permissive conditions" are maintained (see further). 
Cooperative effects of GM1 and NGF in rescuing magnocellular cholinergic neurons: considerations on the mechanisms

The results obtained with GM1 are comparable to those ensuing from the i.c.v. administration of NGF in analogous situations [42 44], (cf. also [6, 7]), (cf. Fig. 6 and Table 1).

Table 1 Effect of various doses of GM1 administered in combination with NGF on ChAT activity in the NBM of
rats 30 days after unilateral decortication

\begin{tabular}{|l|c|c|}
\hline \multirow{2}{*}{ Group } & $\begin{array}{c}\text { Experiment with effective }{ }^{*} \text { dose of } \\
\text { GM1 }\end{array}$ & $\begin{array}{c}\text { Experiment with ineffective } \\
\text { GM1 dose of }\end{array}$ \\
\cline { 2 - 3 } & ChAT activity (\% of control) & ChAT activity (\% of control) \\
\hline Lesion + vehicle & $54^{*}$ & $65^{*}$ \\
\hline Lesion + GM1 & $107^{*}$ & $68^{*}$ \\
\hline Lesion + NGF ${ }^{\circ}$ & 88 & 109 \\
\hline Lesion + GM1 + NGF & $120^{*}$ & $121^{*}$ \\
\hline
\end{tabular}

Effective dose of GM1: $5 \mathrm{mg} / \mathrm{kg}$ per day and ineffective dose: $0.5 \mathrm{mg} / \mathrm{kg}$ per day - i.c.v. for 7 days

- NGF dose: $12 \mu \mathrm{g}$ per day - i.c.v. for 7 days

*Significantly different from control at $P<0.01$ (from [33] modified)

In the series of experiments carried out on the NBM lesioned model $[26,28,29]$ and on the model with cortical devascularization $[33,45]$, (cf. also [10]) a cooperative effect of GM1 and NGF in conditions of combined administration of the two agents, was observed (cf. Fig. 6 and Table 1). Not only a full protection of the cholinergic neurons from retrograde cell shrinkage and loss of neuritic extensions, but also an apparent increase in the number of ChAT immunoreactive processes in the neuropil was found in these conditions [33]. The cooperative effect of GM1 and NGF on ChAT activity (see Table 1) occurs both when an effective and ineffective dose of GM1 were used. These results fit with those obtained on an NBM lesioned model [28, 29], (Fig. 6) where the combined effect of NGF and GM1 at high and low (ineffective) dose of the latter was also found.

Interestingly, after decortication, treatment with either NGF or GM1 increased significantly, over control levels, ChAT activity in the remainder of the ipsilateral cortex, and combined administration of both agents resulted in a $100 \%$ increase of the enzyme activity in the same region [33]. Very recently combined effects of GM1 with NGF in the ipsilateral NBM and in the cortical area surrounding the le- sioned place have been recapitulated in the non-human primate [45].

Although there is still no definite information on the nature of the synergistic effects of NGF and GM1, several mechanisms may be postulated $[28,29,33,45]$, (cf. also [ 10]). The interaction of the ganglioside with endogenous tro- 


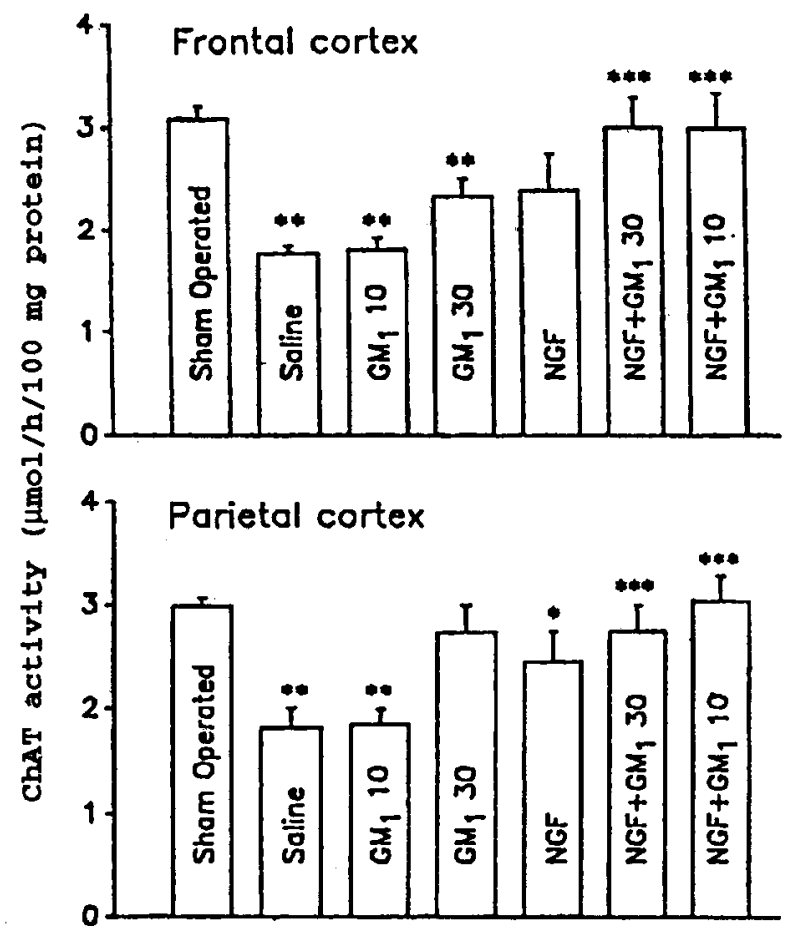

Fig. 6. Effect of various doses of GM1 administered in combination with NGF on ChAT activity in the cortex of rats 21 days after unilateral lesion of NBM. Doses of GM1: 10 or $30 \mathrm{mg} / \mathrm{kg}$ per day (as indicated) for 21 days, i.p.; dose of NGF: $10 \mu \mathrm{g}$, twice a week, for 21 days, i.c.v.; ${ }^{*} P<0.05 ;{ }^{* *} P<0.01$ versus sham - operated ${ }^{* * *} P<$ 0.01 versus saline-treated (from [29], with permission).

factors could be accurately controlled. Interestingly, in a situation in vivo, during postlesion gliosis, the interaction of GM1 with glia elements has been recently described [46]; this could be of significance for the regulation of the glia produced neurotrophic factors, especially NGF. Validation of the ganglioside-trophic factor cooperativity hypothesis will require further investigations of the molecular mechanisms underlying their interactions.

\section{Final remarks}

The data reviewed here showing beneficial effects of gangliosides in rescuing the cholinergic neurons of experimentally damaged brain seem to provide an encouraging element in expectations for future potential therapeutical importance of gangliosides in treating some degenerative human pathologies. The more so as some positive trials concerning these and other noxa already exist (e.g. $[47,48])$. However, the mechanism of ganglioside action still remains elusive. Whether GM1 alone or in combination with NGF will truly serve as a useful clinical therapy rests in the further development of basic research.

\section{REFERENCES}

1. Fibiger, H.C. (1991) Cholinergic mechanisms in learning, memory and dementia: a review of recent evidence. Trends Neurosci. 14, 220 - 223.

2. Perry, E.K., Johnson, M., Kerwin, J.M., Piggot, M.A., Court, J.A., Shaw, P.J., Ince, P.G., Brown, A. \& Perry, R.H. (1992) Convergent cholinergic activities in aging and Alzheimer's disease. Neurobiol. Aging 13, 393 - 400.

3. Traub, M. \& Freedman, S.B. (1992) The implication of current therapeutic approaches for the cholinergic hypothesis of dementia. Dementia 3, 189 - 192.

4. Pepeu, G., Casamenti, F., Marconcini-Pepeu, I. \& Scali, C. (1993) The brain cholinergic system in ageing mammals. J. Reprod. Fert. (Suppl.) 46, $155-162$.

5. Kumar, V. \& Calache, M. (1991) Treatment of Alzheimer's disease with cholinergic drugs. Int. J. Clin. Pharm. 29, 23 - 37.

6. Lapchak, P.A. (1992) Therapeutic potential for nerve growth factor in Alzheimer's disease: insights from pharmacological studies using lesioned central cholinergic neurons. Rev. Neurosci. 3, 109 - 119.

7. Vantini, G. \& Skaper, S.D. (1992) Neurotrophic factors: from physiology to pharmacology? Pharmacol. Res. 26, 1 - 15.

8. Oderfeld-Nowak, B., Wójcik, M., Ułas, J. \& Potempska, A. (1981) Effect of chronic ganglioside administration on recovery processes in rat hippocampus after brain lesions; in Gangliosides in Neurological and Neuromuscular Function (Rapport, M. \& Gorio, A., eds.) pp. 197 - 209, Raven Press, New York.

9. Wójcik, M., Ułas, J. \& Oderfeld-Nowak, B. (1982) The stimulating effect of ganglioside injections on the recovery of choline acetyltransferase and acetylcholinesterase activities in the hippocampus of the rat after septal lesions. Neuroscience 7, 495 - 499.

10. Cuello, A.C. (1990) Glycosphingolipids that can regulate nerve growth and repair. Adv. Pharmacol. 21, 1 - 50 .

11. Ledeen, R.W. (1985) Gangliosides of the neuron. Trends Neurosci. 8, 169 - 174.

12. Karpiak, S., Mahadik, S.P. \& Wakade, C.G. (1990) Ganglioside reduction of ischemic injury. Crit. Rev. Neurobiol. 5, 221 - 237. 
13. Offano, G., Benvegnu, D., Bonetti, A.C., Facci, L., Leon, A., Orlando, P., Ghidoni, R. \& Tettamanti, G. (1980) Interactions of GM1 ganglioside with crude rat brain neuronal membranes. J. Neurochem. 35, 861 - 866.

14. Ogura, K. \& Handa, S. (1988) Metabolism of exogenous gangliosides GM1 and chemically modified GM1 in mice. J. Biochem. (Tokyo) 104, $87-92$.

15. Ghidoni, R., Fiorilli, A., Trinchera, M., Venerando, B., Chigorno, V. \& Tettamanti, G. (1989) Uptake, cell penetration and metabolic processing of exogenously administered GM1 ganglioside in rat brain. Neurochem. Int. 15, 455 -465 .

16. Manev, H., Favaron, M., Vicini, S. \& Guidotti, A. (1990) Ganglioside-mediated protection from glutamate-induced neuronal death. Acta Neurobiol. Exp. 50, 475 - 488.

17. Pepeu, G., Oderfeld-Nowak, B. \& Casamenti, F. (1993) CNS pharmacology of gangliosides. Prog. Brain Res. (in press).

18. Oderfeld-Nowak, B., Skup, M., Ułas, J., Jezierska, M., Gradkowska, M., Zaremba, M. (1984) Effect of GM1 ganglioside treatment on postlesion responses of cholinergic neurons in rat hippocampus after various partial deafferentations. J. Neurosci. Res. 12, 409 - 420.

19. Grądkowska, M., Skup, M., Kiedrowski, L., Calzolari, S. \& Oderfeld-Nowak, B. (1986) The effect of GM1 ganglioside on cholinergic and serotoninergic systems in the rat hippocampus following partial denervation is dependent on the degree of fiber degeneration. Brain Res. 375, $417-422$.

20. Skup, M., Gradkowska, M., Ulas, J. \& Oderfeld-Nowak, B. (1987) Analysis of the time course of GM1 ganglioside effect on changes in choline acetyltransferase activity in partially denervated rat hippocampus. Acta Neurobiol. Exp. 47, 199 - 211.

21. Oderfeld-Nowak, B., Gradkowska, M., Zaremba, M. \& Kiedrowski, L. (1988) Protection against secondary degeneration of nerve terminals in target structure - a possible mechanism to account for early beneficial effects of ganglioside treatment in injured brain; in New Trends in Ganglioside Research: Neurochemical and Neurodegenerative Aspects (Ledeen, R.W., Hogan, E.L., Tettamanti, G., Yates, A.J., Yu, R.K., eds.) pp. 567 -577, Fidia Res. Ser. 14, Liviana Press.

22. Cannella, M.S., Oderfeld-Nowak, B., Gradkowska, M., Skup, M., Garofalo, L., Cuello, A.C. \& Ledeen, R.W. (1990) Derivatives of ganglioside GM1 as neuronotrophic agents: comparison of in vivo and in vitro effects. Brain Res. 513, 286 294.

23. Ledeen, R.W., Wu, G., Cannella, M.S., Oderfeld-Nowak, B. \& Cuello, A.C. (1990) Gangliosides as neurotrophic agents: studies on mechanisms of actions. Acta Neurobiol. Exp. 50, 430.

24. Pedata, F., Giovannelli, L. \& Pepeu, G. (1984) GM1 ganglioside facilitates the recovery of high affinity choline uptake in the cerebral cortex of rats with a lesion of the nucleus basalis magnocellularis. J. Neurosci. Res. 12, 421 - 427.

25. Casamenti, F., Bracco, L., Bartolini, L. \& Pepeu, G. (1985) Effects of ganglioside treatment in rats with a lesion of the cholinergic forebrain nuclei. Brain Res. 338, 45 - 52.

26. Casamenti, F, Di Patre, P.L., Milan, F, Petrelli, L. \& Pepeu, G. (1989) Effects of nerve growth factor and GM1 ganglioside on the number of cholinergic neurons in rats with unilateral lesion of the nucleus basalis. Neurosci. Lett. 103, $87-91$.

27. Di Patre, P.L., Abbomonti, A., Bartolini, L. \& Pepeu, G. (1989) GM1 ganglioside counteracts cholinergic and behavioural deficits induced in the rat by intracerebral injection of vincristine. Eur. J. Pharmacol. 162, 43 - 50.

28. Di Patre, P.L., Casamenti, F., Cenni, A. \& Pepeu, G. (1989) Interaction between nerve growth factor and GM1 monosialoganglioside in preventing cortical choline acetyltransferase and high affinity choline uptake decrease after lesion of the nucleus basalis. Brain Res. 480, 219 $-224$.

29. Casamenti, F., Milan, F. \& Pepeu, G. (1990) Lesions of the nucleus basalis magnocellularis in the rat: morphological, biochemical and behavioral reparative effect of nerve growth factor and ganglioside GM1. Acta Neurobiol. Exp. 50, 461 - 473 .

30. Sofroniew, M.V., Pearson, R.C.A., Cuello, A.C., Tagari, P.C. \& Stephens, P.H. (1986) Parenterally administered GM1 ganglioside prevents retrograde degeneration of cholinergic cells of the rat basal forebrain. Brain Res. 398, 393 - 396.

31. Tuszynski, M.H., Armstrong, D.M. \& Gage, F.H. (1990) Basal forebrain cell loss following fimbria fornix transection. Brain Res. 508, 241 - 248.

32. Cuello, A.C., Stephens, P.H., Tagari, P.C. \& Sofroniew, M.V., Pearson, R.C.A. (1986) Retrograde changes in the nucleus basalis of the rat, caused by cortical damage, are prevented by exogenous ganglioside GM1. Brain Res. 376, $373-377$.

33. Cuello, A.C., Garofalo, L., Kenigsberg, R.L. \& Maysinger, D. (1989) Ganglioside potentiate in 
vivo and in vitro effects of nerve growth factor on central cholinergic neurons. Proc. Natl. Acad. Sci. U.S.A. 86, $2056-2060$.

34. Elliott, P.J., Garofalo, L. \& Cuello, A.C. (1989) Limited neocortical devascularizing lesions causing deficits in memory retention and choline acetyltransferase activity-effects of the monosialoganglioside GM1. Neuroscience 31, 63 $-76$.

35. Maysinger, D., Herrera-Marschitz, M., Carlsson, A., Garofalo, L., Cuello, A.C. \& Ungerstedt, U. (1988) Striatal and cortical acetylcholine release in vivo in rats with unilateral decortication: Effects of treatment with monosialoganglioside GM1. Brain Res. 461, 355 - 360.

36. Maysinger, D., Garofalo, L., Jalsenjak, I. \& Cuello, A.C. (1989) Effects of microcapsulated monosialoganglioside GM1 on cholinergic neurons. Brain Res. 496, 165 - 172.

37. Pióro, E.P., Maysinger, D., Ervin, F.R., Desypris, G. \& Cuello, A.C. (1993) Primate nucleus basalis of Meynert P 75NGFR containing cholinergic neurons are protected from retrograde degeneration by the ganglioside GM1. Neuroscience 53, $49-56$.

38. Emerich, D.F., Walsh, T.J. (1991) Ganglioside AGF2 prevents cognitive impairments and cholinergic cell loss following intraventricular colchicine. Exp. Neurol. 112, 328 - 337.

39. Stephens, P.H., Tagari, T.C. \& Cuello, A.C. (1988) Retrograde degeneration of basal forebrain cholinergic neurons after neurotoxin lesion of the neocortex: application of ganglioside GM1. Neurochem. Int. 12, 475 - 481.

40. Stephens, P.H., Tagari, P.C., Garofalo, L., Maysinger, D., Protte, M. \& Cuello, A.C. (1987) Neural plasticity of basal cholinergic neurons: Effects of gangliosides. Neurosci. Lett. 80, 80-84.

41. Hadjiconstantinou, M., Karadshen, N.S., Rat$\tan$, A.K., Tejwani, G.A., Fitkin, J.G. \& Neff, N.H. (1991) GM1 ganglioside enhances cholinergic parameters in the brain of senescent rats. Neuroscience 46, 681 - 686 .

42. Fusco, M., Oderfeld-Nowak, B., Vantini, G., Schiavo, N., Grądkowska, M., Zaremba, M. \& Leon, A. (1989) Nerve growth factor affects uninjured, adult rat septohippocampal cholinergic neurons. Neuroscience 33, 47 - 52.

43. Tuszynski, M.H., Amaral, D.G. \& Gage, F.H. (1990) Nerve growth factor infusion in the primate brain reduces lesion-induced cholinergic neuronal degeneration. J. Neurosci. 10, 3604 - 3614.

44. Koliatsos, V.E., Clatterbuck, R.E., Nanta, H.J., Knusel, B., Burton, L.E., Hefti, F., Mobley, W.C.
\& Price, D.L. (1991) Human nerve growth factor prevents degeneration of basal forebrain cholinergic neurons in primates. Ann. Neurol.30, $831-840$.

45. Liberini, P., Pioro, E.P., Maysinger, D., Ervin, F.H. \& Cuello, A.C. (1993) Long-term protective effects of human recombinant nerve growth factor and monosialoganglioside-GM1 treatment on primate nucleus basalis cholinergic neurons after neocortical infarction. Neuroscience 53, 625 - 637.

46. Oderfeld-Nowak, B., Jegliński, W., Skup, M., Skangiel-Kramska, J., Zaremba, M. \& Koczyk, D. (1993) Differential effects of GM1 ganglioside treatment on glial fibrillary acidic protein content in the rat septum and hippocampus after partial interruption of their connections. J. Neurochem. 61, 116-119.

47. Svennerholm, L., Gottfries, C.G., Bleunow, K., Freedman, P., Karlsson, J., Mannson, J.E., Toffano, G. \& Wallin, A. (1990) Parenteral administration of GM1 ganglioside in Alzheimer patients. Acta Neurol. Scand. 81, 48 53.

48. Geisler, F.H., Dorsey, F.C. \& Coleman, W.P. (1991) Recovery of motor function after spinal cord injury - a randomized, placebo-controlled trial with GM1-ganglioside. New Engl. J. Med. 324, 1829 - 1838. 